\title{
甘肃中部史前农业发展的源流: 以甘肃秦安和礼县为例
}

\author{
安成邦 ${ }^{(1)}$, 吉笉学 ${ }^{(12)}$, 陈发虎 ${ }^{(1)}$, 董广辉 ${ }^{\mathbb{1}}$, 王辉 ${ }^{(3)}$, 董惟妙 ${ }^{(1)}$, 赵雪野 ${ }^{(3)}$ \\ (1) 兰州大学西部环境教育部重点实验室, 兰州 730000; \\ (2) 深圳考古研究所, 深圳 518028; \\ (3) 甘肃省考古与文物研究所, 兰州 730000 \\ E-mail: cban@1zu.edu.cn
}

2009-12-06 收稿, 2010-01-07 接受

国家自然科学基金创新群体-西部环境项目(40721061)、国家科技支撑计划(2006BAK21B02)和国家自然科学基金(40601094)资助

\begin{abstract}
摘要 以甘肃省秦安和礼县为中心的环境考古研究表明, 8 7.3 ka BP 之间的大地湾一期栽培作 物㯟数量少, 出现频率低, 并且个体较小. 而 $6.4 \mathrm{ka} \mathrm{BP}$ 之后的半坡期农作物出现频率空前提 高, 籽实饱满. 这说明在由大地湾一期文化向仰韶文化过渡过程中栽培作物㯟成功实现了向农 作物的过渡。本区粟作农业的发展和兴盛略晚于中原地区。气候变化是本区农业发展的重要影 响因素，本区在全新世中期气候较为湿润，为仰韶文化时期和常山下层文化时期农业的兴盛提 供了良好的水热条件, 并且出现了喜湿热的水稻. $4 \mathrm{ka} \mathrm{BP}$ 以后, 气候趋向千旱, 齐家文化中农 业水平开始下降, 寺洼文化以畜牧经济为主, 一直到东周时期农业才开始复苏, 并出现了大麦 和小麦等新的作物品种，粟作农业被多元化的农业所取代.
\end{abstract}

关键词

农业

新石器文化

秦安县

礼县
农业的起源和发展是人类历史上里程碑式的事 件. 根据 Diamond ${ }^{[1]}$ 的观点, 世界主要农业起源中 心，如中东“新月形地带”、中国、中美洲、安第斯亚马逊河地区、美国东部、非洲撒哈拉地区、西非 热带雨林地区、埃塞俄比亚以及新几内亚等基本都 经历了一个由采集经济到农业经济的漫长历史发展 阶段. 例如, 在巴布亚新几内亚, Wahgi 流域 Kuk 遗 址周围地区在全新世早期(10.2 9.9 ka BP)就存在营 养价值和热量较高的芋头、香蕉以及生姜等植物. 这里的采集者为了满足对食物的需要, 用石器工具 采掘芋头. 到了 6.9 6.5 ka BP 时期, 随着环境的变 化, 河谷中的森林环境逐渐变成草地, 人们开始在 湿地边缘的土包上设畦种地, 筑渠导水, 驯化香蕉 等植物, 并对芋头和生姜等淀粉类植物做进一步的 加工和处理 ${ }^{[2]}$.

中国是世界农业起源的中心之一, 安志敏 ${ }^{[3]}$ 根据 农作物、农业工具以及家畜的发现情况提出中国农业 自成体系, 粟的驯化和栽培可能起源于黄河流域.
Crawford ${ }^{[4]}$ 认为, 中国北方草原与森林过渡带的地理 环境与中东“新月形地带”相近，并就此提出中国北 方农业也可能首先产生于这一地区的结论. 有学者 认为, 在探讨中国北方旱地粟作农业起源的问题上, 粟和㯟应该区别对待. 粟起源于中原地区，而㯟的起 源除中原外, 也许还要偏北一些 ${ }^{[5,6]}$. 近年来内蒙古 赤峰兴隆沟遗址的发掘证明, 粟和㯟均起源于农牧 交错带 ${ }^{[7]}$, 但两种农作物粟和㯟的比例悬殊. 陈文 华 ${ }^{[8]}$ 将中国农业的发生和发展过程分为 3 个阶段, 即 模仿期、刀耕火种期以及耤耕期. 石兴邦 ${ }^{[9]}$ 认为采集 经济向农业经济过渡经历了 4 个阶段, 其中最后阶段 是锄耕农业阶段(10 8 ka BP), 开始刀耕火种, 相当 于前仰韶文化时期，它的最终发展结果导致了农业 的产生. 但是中国农业起源研究材料的缺乏导致这 些观点在很大程度上依然是假说, 需要更多的研究 材料来证实. 为此, 我们以甘肃的秦安县(个别地点 在庄浪县)和礼县(图 1)为中心开展环境考古研究, 探 讨研究区的农业发展, 明确不同时期农作物的种类 


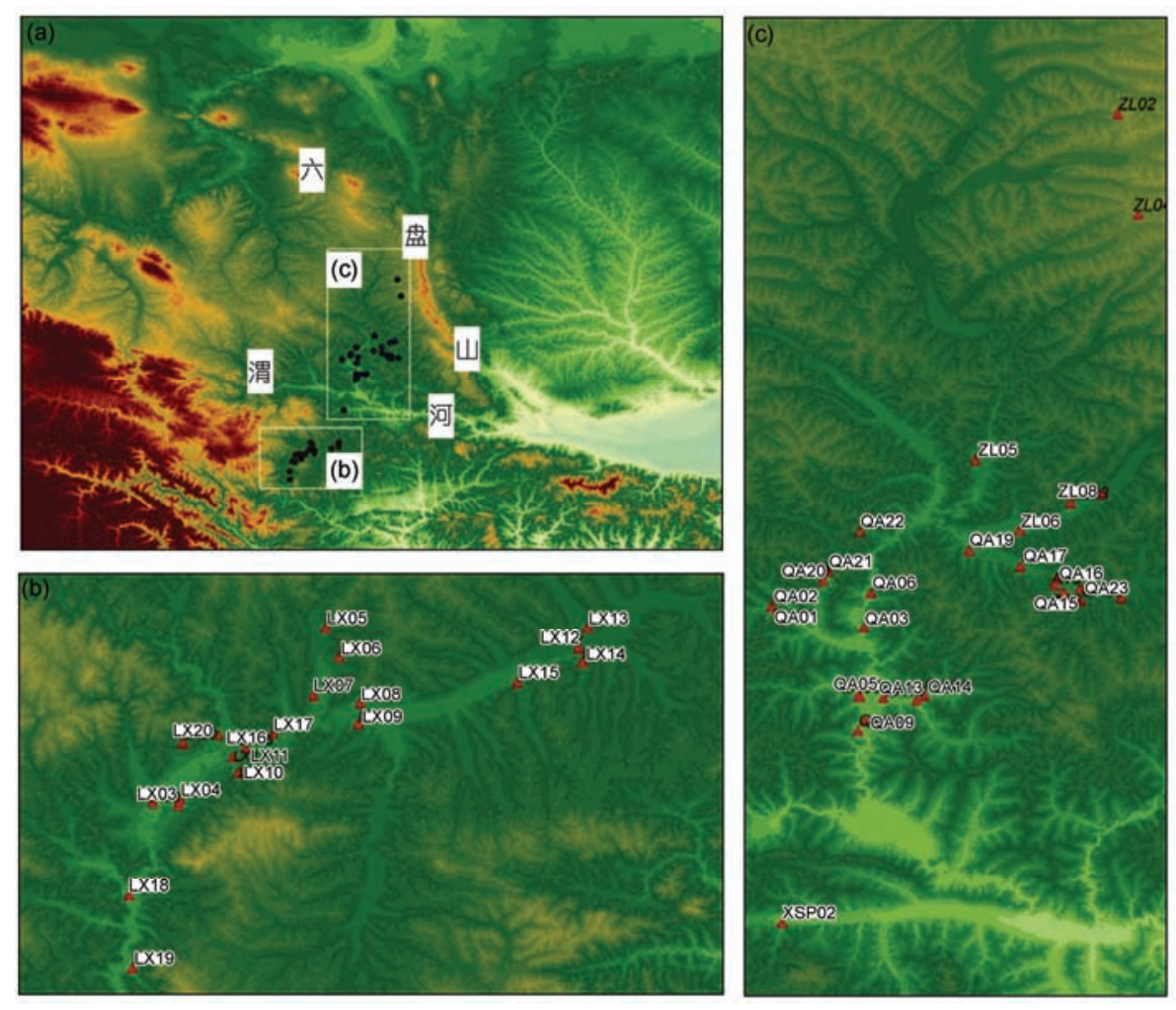

图 1 研究区域和研究地点

(a) 甘肃中部; (b) 礼县; (c) 秦安县. 圆点和三角符号代表研究过的地点, 三角符号旁的字母数字组合代表研究地点的实验室编号

和丰富程度, 尤其是粟和㯟两种作物的数量和种子 个体变化过程，进而探讨区域原始农业的发展过程. 这两地考古文化类型齐全, 农业发展的历史悠久, 是 甘肃中部农业发展的代表性地点, 所以我们选择在 两地开展集中研究.

\section{1 研究区域和研究方法}

为了全面系统地了解研究区全新世以来的农业 发展状况, 我们在以秦安为中心的葫芦河流域和以 礼县为中心的西汉水流域展开大范围的环境考古调 查(图 1).

秦安县位于黄土高原西部的葫芦河流域, 年降 水量为 $500 \sim 600 \mathrm{~mm}$, 黄土沟谷地形发育. 礼县位 于西汉水上游的西秦岭中, 山高沟深, 境内海拔最 高 $3312 \mathrm{~m}$, 最低 $1080 \mathrm{~m}$, 年降水量大致与秦安县 相当.

样品采集主要采取浮选法, 所有样品以孔径为 $0.315 \mathrm{~mm}$ 的篮网收集轻浮物, 用 $1.25 \mathrm{~mm}$ 孔径的篮 网收集重浮物. 样品在室内自然风干后按 $0.315 \mathrm{~mm}$,
$0.63 \mathrm{~mm}$ 和 $1.25 \mathrm{~mm}$ 孔径进行分选后在 $\times 40$ 的显微镜 下进行种属鉴定. 粟和乘的鉴定一般都采用形态学 辨识加上个体测量的方法 ${ }^{[7,10]}$, 我们同样采用了这一 方法. 根据孔昭宸等人 ${ }^{[10]}$ 的研究, 粟的个体要比乘 偏小，也就是说粟的籽粒的长度和宽度比乘的小; 同 时, 粟的长度与宽度比较接近, 形状比㯟圆, 且其胚 部的形状和㯟的不同; 另外, 还有一些细部特征的差 别，具体可以参见文献[10]. 鉴于粟和㯟的区分往往 会引起不同鉴定人的争议, 我们对本研究中鉴定的 粟和㯟进行了验证. 我们设计的验证原理和方法详 述如下. 植物学家根据光合作用形式将植物分成 $\mathrm{C}_{3}$, $\mathrm{C}_{4}$ 和 CAM 3 类. 粟和黍都属于 $\mathrm{C}_{4}$ 植物，根据进人维 管束鞘的 $\mathrm{C}_{4}$ 化合物和脱羧反应的不同, $\mathrm{C}_{4}$ 植物光合 作用途径存在 3 种类型 ${ }^{[1]}$ : NADP-ME 型(粟即属于这 一类型)、NAD-ME 型(㯟属于这一类型)和 PEP-CK 型. 粟和㯟的光合作用途径不同, 研究表明 ${ }^{[11,12]}$, 粟 较乘的碳同位素应该总体偏正.如果我们鉴定的粟 和㯟的区分是正确的话，它们就应该表现出这种同 位素上的差异．考虑到炭化过程对植物同位素的影 
响, 我们选取在相同地点和层位中发现的粟和㯟进 行同位素的比较, 可以有效地去除炭化过程可能产 生的影响. 鉴于纬度因素对植物碳同位素的影响, 我 们把秦安和礼县的样品分开进行比较. 秦安的粟的 $\delta^{13} \mathrm{C}$ 值介于 $-11.36 \% 0 \sim-9.78 \%$ 之间, 平均值为 $-10.39 \%$ ；秘的 $\delta^{13} \mathrm{C}$ 值介于 $-11.85 \%$ - $10.02 \%$ 之间, 平均值为 $-10.87 \%$ 。 礼县的粟的 $\delta^{13} \mathrm{C}$ 值介于 $-11.76 \%$ 。 $\sim-9.59 \%$ 之之间, 平均值为 $-10.46 \%$; 㯟的 $\delta^{13} \mathrm{C}$ 值则处 于 $-11.93 \%$ - $10.49 \%$ 。之间, 平均值为 $-11.26 \%$. 两 地的粟都较㯟的碳同位素偏正, 证明我们的鉴定结 果总体上是可信的.

环境考古样品的采集遵循两个原则：首先需要 保证灰坑、房屋以及悎穴等考古遗迹地层关系明确; 其次，在缺乏明确遗迹单位的情况下，选择在文化堆 积比较单一的地层中采样. 整个研究区共采集植物 样品 96 份, 其中秦安 71 份, 礼县 25 份. 研究区大地 湾一期及其之前的植物样品主要来源于 2004 和 2006 年大地湾遗址的发掘. 本次调查主要基于 20 世纪 80 年代全国文物普查发现的考古遗址. 因此, 本文采用 最新的甘肃地区史前文化的分期方案来确定采样点 的时代和文化属性 ${ }^{[13]}$. 这一分期方案和以前我们发 表的文章中 ${ }^{[14,15]}$ 的文化分期年代略有差异，具体是： 大地湾一期文化(8 7.3 ka BP) 一仰韶文化半坡期 (6.3 6.0 ka BP) 一仰韶文化庙底沟期(5.7 5.5 ka BP) $\rightarrow$ 仰韶文化晚期 $(5.5 \sim 5.0 \mathrm{ka} \mathrm{BP}) \rightarrow$ 常山下层文化 $(5 \sim 4.5 \mathrm{ka} \mathrm{BP}) \rightarrow$ 齐家文化桥村类型 $(4.4 \sim 3.8 \mathrm{ka} \mathrm{BP}) \rightarrow$ 寺洼文化 (3.6 2.6 ka BP) 一东周 (2.7 2.4 ka BP). 礼 县的考古调查还参考了西汉水流域早期秦文化调查
的结果 ${ }^{[16]}$.

\section{2 结果}

本次研究中发现了粟、㯟、水稻、小麦、大麦等 植物(图 2). 所见㯟多为长鼓圆形, 肧区近正三角形, 其平均尺寸为长 $1.58 \mathrm{~mm}$, 宽 $1.43 \mathrm{~mm}$. 粟的籽粒长 度和宽度比㯟小, 形状近正圆, 顶端较平, 平均粒长 $0.98 \mathrm{~mm}$, 宽 $0.97 \mathrm{~mm}$. 水稻籽粒较扁平，腹部有明显 的凹槽, 平均粒长 $6.34 \mathrm{~mm}$, 宽 $3.32 \mathrm{~mm}$. 大麦平均 粒长 $5.77 \mathrm{~mm}$, 宽 $3.00 \mathrm{~mm}$, 籽粒呈纺锤形, 一头尖, 另一头有破损, 肧部与腹沟都很清楚. 小麦平均粒长 $4.30 \mathrm{~mm}$, 宽 $2.78 \mathrm{~mm}$, 形状为椭圆形或卵圆形, 肧部 与腹沟都清晰可辨, 籽粒尾端圆. 其中, 粟所占的比 例最大, 秘其次. 粟和㯟的数量变化具体如图 3 所示.

\section{1 大地湾一期(8 7.3 ka BP)及其之前}

在 2004 和 2006 年大地湾遗址的发掘中, 大地湾 一期以前的地层中未发现㯟的种子, 而大地湾一期 文化层中只有㯟，没有粟. 由于这一时期样品中的植 物种子总数均小于 10 , 因而㯟在整个农作物中所占 的比例缺乏统计意义.

\section{2 半坡期(6.3 6.0 ka BP)}

这一时期的农作物种子大量出现. QA08 地点样 品中, 秘和粟的数量达到了 240 粒. 大地湾遗址半坡 期围沟外侧剖面 QA10-JB01 地点中两种作物的数量 也有 160 多粒. 礼县 LX12 地点半坡期灰层中也发现 了 60 多粒两种植物的种子.

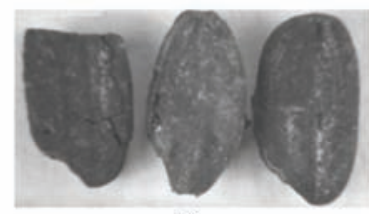

(a)

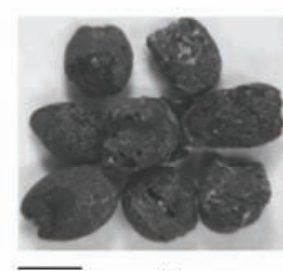

(c)

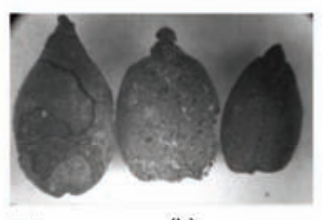

$1 \overline{\mathrm{mm}}$

(b)

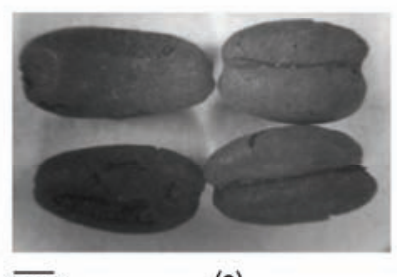

(e)

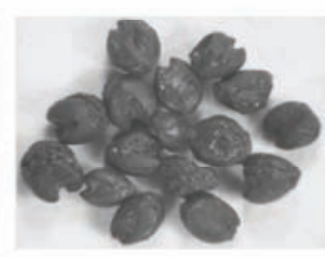

(d) $\overline{1 \mathrm{~mm}}$

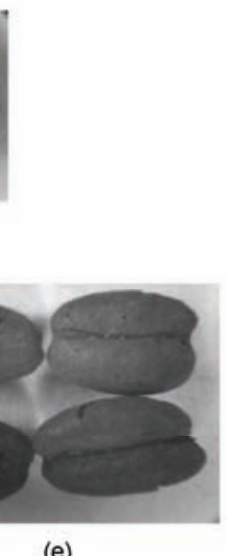

图 2 研究中发现的农作物

(a) 水稻; (b) 大麦; (c) 㯟; (d) 粟; (e) 小麦 


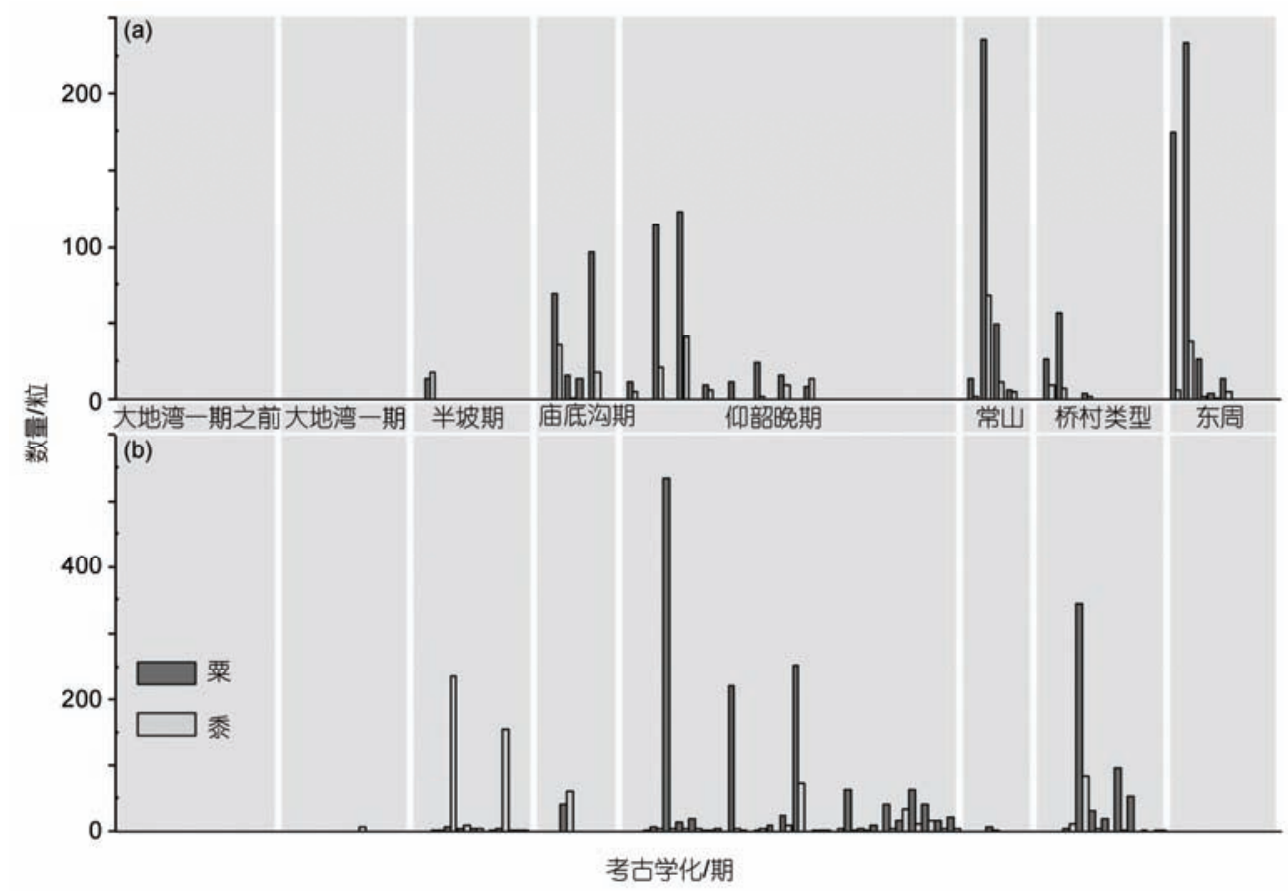

图 3 秦安 $(a)$ 和礼县 $(b)$ 大地湾一期文化前到东周时期粟和㯟的数量变化

\section{3 庙底沟期(5.7 5.5 ka BP)}

这一时期, 礼县 4 个样品显示粟已经取代了㯟, 成为该地区的主要农作物. 各样品中粟所占农作物 比重分别为 66\%, 84\%, 94\%和 100\%. 但在秦安, 仅采 集到一个该文化期的样品, 并且从粟与㯟的数量来 看, 㯟略多于粟. 综合来看, 粟开始超越㯟成为最主 要的农作物.

\section{4 仰韶文化晚期(5.5 5.0 ka BP)}

仰韶文化晚期的农作物延续庙底沟时期的传统, 保持以粟为主体的状况. 秦安样品的统计显示, 粟占 $89 \%$ ，而㯟仅为 $11 \%$. 礼县粟和㯟的比例分别为 $77 \%$ 和 $23 \%$. 同时, 在礼县的一个地点还发现了 7 粒炭化 的稻米.

\section{5 常山下层文化(5 4.5 ka BP)与齐家文化桥村 类型(4.4 3.8 ka BP)}

在礼县, 常山时期的农作物种植基本与仰韶晚 期相当, 也是以粟为主. 而秦安由于各样品中种子数 量很少, 因而难以详细描述其面貌.

齐家文化桥村类型时期的农业发展水平大致与 仰韶晚期相当. 其中秦安发现的㯟和粟的数量比仰
韶文化晚期略有降低. 而礼县的样品中浮选出的种 子数量大致和仰韶文化晚期的持平.

\section{6 东周(2.7 2.4 ka BP)}

本次调查未能在寺洼文化中采集到样品. 秦安没 有发现东周时期的地层, 礼县东周时期的农业规模显 然较大, 发现了大量的作物种子, 并且在研究区出现 了小麦、大麦等品种, 农业品种出现多元化的趋势.

\section{3 讨论}

大地湾一期文化以前的地层中没有发现作物种 子. 大地湾一期文化的地层中, 从单个样品来看, 一 个样品发现了 1 粒㯟, 而另一样品发现了 7 粒㯟, 这 说明㯟已经开始引起先民的注意，人们已经开始利 用它.

根据农作物种子密度计算, 在大地湾一期文化 中, 农作物的出现频率仅为 $0.15 \sim 0.21$ 粒/L, 但从半 坡期开始, 秦安农作物的密度突然跃至 60 粒/L, 同 样地, 在礼县这一数量也达到 12 粒/L. 一切均表明, 半坡期农业得到了长足的发展, 农作物已经从各种 杂草中脱颖而出, 占据了主导地位. 半坡时期农作物 主要以乘为主, 而粟相对较少. 秦安半坡期的㯟占农 作物总量的 $92 \%$, 而粟仅占 $8 \%$; 礼县采集的样品中, 
也是㯟略多于粟. 这与刘长江等人 ${ }^{[17]}$ 对大地湾遗址 所做的浮选结果基本一致.

到了庙底沟期，粟的数量远远大于半坡期，在发 现的作物中逐渐占主要地位. 由此可见, 粟大致在庙 底沟期突然取代了秘并且成为主要农作物。值得一 提的是，在礼县的一个地点还发现了稻米遗存.

仰韶晚期的农作物延续庙底沟时期的传统，保 持以粟为主体的状况. 秦安样品的统计显示, 粟占 $89 \%$, 而㯟仅为 $11 \%$. 同时期礼县粟和㯟的比例分别 为 $77 \%$ 和 $23 \%$. 同时, 在礼县的一个研究地点还发现 了 7 粒炭化的稻米.

在礼县，常山时期的农作物种植基本与仰韶晚 期相当, 也是以粟为主. 而秦安由于各样品中种子数 量很少, 因而难以详细描述其面貌, 可能此时秦安史 前农业的发展受到了某种因素的影响.

齐家文化桥村类型时期的农业发展水平略有下 降, 但两地的史前农业发展有一定的差别. 其中礼县 发现的黍和粟的数量比仰韶文化晚期略有降低. 而 秦安县的样品中浮选出的种子数量大致和仰韶文化 晚期的持平.

齐家文化以后的寺洼文化中没能采集到样品， 这固然可能和我们的野外调查力度有关, 但也表明 寺洼文化时期，文化规模明显比齐家文化偏小. 东周 时期本区农业开始出现了多元化的发展.

秦安和礼县的农业考古调查表明, 在 8 7.3 ka BP 之间的大地湾一期文化时期研究区虽然发现少量㯟 类农作物遗存, 然而数量非常少, 且种子个体比较小. 到了仰韶文化半坡期, 㯟类农作物遗存在样品中的 比重突然增加, 农作物种子个体较大, 籽实饱满. 到 了庙底沟时期研究区内以㯟为主要农作物的格局可 能随着关中地区庙底沟文化的向西扩散而被打破, 开始出现了以农作物粟为主的特点. 同时, 礼县等地 出现稻米等喜湿热型农作物. 此后, 粟始终是主要农 作物品种. 到了东周, 小麦和大麦突然出现, 农业品 种出现多元化的趋势, 显然, 此时的史前农业受到了 外来因素的很大影响, 具体原因还有待于进一步研究.

上述发现表明，甘肃中部不是粟作农业的起源 地, 本区粟作农业的发展和兴盛略晚于中原地区. 半 坡时期是以㯟和粟为代表的旱作农业在本区的兴起
阶段，农业似乎在一夜之间走向了成熟，和此前的大 地湾一期的农业面貌截然不同. 这种“跳跃式的快速 发展”的农业状况也暗示了外来农业对本区的影响. 庙底沟期和仰韶晚期是本区农业的大发展阶段，不 仅遗址的数量比此前大大增加 ${ }^{[18]}$, 而且遗址地层中 浮选出的农作物种子数量也大大增加, 粟开始逐步 超过㯟成为最主要的农作物. 常山下层文化时期可 能是本区原始农业的兴盛期，不仅在地层中浮选出 了大量的农作物种子, 而且这一时期的墓葬中出现 了厚葬的风俗 ${ }^{[19]}$, 表明社会富裕程度大大增加. 齐 家文化时期农业发展水平略有下降，而到了其后的 寺洼文化, 没有发现农作物的种子, 这和国内学者认 为寺洼文化应该以畜牧经济为主的判断一致 ${ }^{[19]}$, 也 和我们以前研究过的齐家文化以后农业的衰落一 致 ${ }^{[15]}$. 一直到东周时期, 本区的农业又开始发展.

同时也可以看出, 本区农业的发展除了文化因 素本身的影响之外, 还受到了气候变化的影响, 我们 的研究 ${ }^{[14]}$ 已经证明, 本区在全新世中期气候较为湿 润，为仰韶文化时期和常山下层文化时期农业的兴 盛提供了良好的水热条件, 并且出现了喜湿热的水 稻. $4 \mathrm{ka} \mathrm{BP}$ 以后, 气候趋向干旱 ${ }^{[15,20]}$, 齐家文化中农 业水平开始下降, 寺洼文化以畜牧经济为主, 一直到 东周时期农业才开始复苏.

\section{4 结论}

8 7.3 ka BP 之间的大地湾一期栽培作物㯟数量 少, 出现频率低. 而 $6.4 \mathrm{ka} \mathrm{BP}$ 之后的半坡期农作物 出现频率空前提高, 籽实饱满. 这说明在由大地湾一 期文化向仰韶文化过渡过程中栽培作物㯟成功实现 了向农作物的过渡. 甘肃中部不是粟作农业的起源 地，本区粟作农业的发展和兴盛略晚于中原地区. 半 坡时期是以㯟和粟为代表的旱作农业在本区的兴起 阶段. 庙底沟期和仰韶晚期是本区农业的大发展阶 段. 齐家文化时期农业发展水平略有下降，其后的寺 洼文化应该以畜牧经济为主，一直到东周时期，本区 的农业又开始发展。本区农业的发展除了受文化因 素本身的影响之外, 气候变化也是重要的影响因素. 当然, 要全面认识本区域农业的发展历程, 还需要更 多的考古发掘的成果和理论研究.

\section{参考文献}

1 Diamond J. Evolution, consequences and future of plant and animal domestication. Nature, 2002, 418: 700-707 
2 Denham T, Haberle S, Lentfer C. New evidence and revised interpretations of early agriculture in Highland New Guinea. Antiquity, 2004, 78: $839-857$

3 安志敏. 中国的史前农业. 考古学报, 1988, 4: 369-381

4 Crawford G W. The transitions to agriculture in Japan. In: Gebauer A B, Price T D, eds. Transitions to Agriculture in Prehistory, Monographs in World Archaeology. Madison: Prehistory Press, 1992. 117-132

5 Underhill P A, Passarino G, Lin A A, et al. The hylogeography of Y chromosome binary haplotypes and the origins of modern human populations. Ann Hum Genet, 2001, 65: 43-62

6 严文明. 农业发生与文明起源. 北京: 科学出版社, 2000. 1-180

7 赵志军. 从兴隆沟遗址浮选结果谈中国北方旱作农业起源问题. 见: 南京师范大学文博系, 编. 东亚古物. 北京: 文物出版社, 2004. 188-199

8 陈文华. 论农业考古. 南昌: 江西教育出版社, 1988. 3-121

9 石兴邦. 下川文化的生态特点与粟作农业的起源. 考古与文物, 2000, 4: 17-35

10 刘长江, 孔昭宸. 粟、乘籽粒的形态比较及其在考古鉴定中的意义. 考古, 2004, 8: 76-83

11 Hattersley P W. $\delta^{13} \mathrm{C}$ Value of $\mathrm{C}_{4}$ types in grasses. Aust J Plant Physiol, 1982, 9: 139—154

12 Schulze E D, Ellis R, Schulze W, et al. Diversity, metabolic types and $\delta^{13} \mathrm{C}$ carbon isotope ratios in the grass flora of Namibia in relation to growth form, precipitation and habitat conditions. Oecologia, 1996, 106: 352-369

13 朗树德. 甘肃秦安县大地湾遗址聚落形态及其演变. 考古, 2003, 6: 83-89

14 An C B, Feng Z D, Tang L Y. Environment change and cultural response between 8000 and 4000 cal. yr BP in the western Loess Plateau, NW China. J Quat Sci, 2004, 19: 529-535

15 An C B, Tang L Y, Barton L, et al. Climatic Change and Cultural Response around 4,000 cal. yr B.P. in the western part of the Chinese Loess Plateau. Quat Res, 2005, 63: 347-352

16 早期秦文化联合考古队. 西汉水上游新石器时代遗址调查简报. 考古与文物, 2004, 6: 3-12

17 刘长江, 孔昭宸, 朗树德. 大地湾遗址农业植物遗存与人类生存的环境探讨. 中原文物, 2004, 4: 26-30

18 水涛. 中国西北地区青铜时代考古论集. 北京：科学出版社, 2001. 147-153

19 水涛. 中国西北地区青铜时代考古论集. 北京: 科学出版社, 2001.110-114

20 An C B, Feng Z D, Barton L. Dry or Humid? Mid-Holocene Humidity Changes in arid and semi-arid China. Quat Sci Rev, 2006, 25: $351-361$ 